\title{
SUPERFÍCIE CURIE DA REGIÃO CENTRAL DE GOIÁS
}

\author{
MARCELO DE LAWRENCE BASSAY BLUM \& AUGUSTO CESAR BITTENCOURT PIRES
}

\begin{abstract}
CURIE SURFACE OF THE GOIÁS CENTRAL REGION The study area is located in the central region of the State of Goiás, between $14^{\circ}$ and $16^{\circ}$ South and $48^{\circ}$ and $51^{\circ}$ West and is a part of the Tocantins Structural Province. Several geophysical surveys were performed in the region starting in the 70's, with the Brazil-Canada Geophysical Project (PGBC) when a regional aeromagnetic survey took place.

Magnetic interpretation of prismatic models allows the evaluation of depths where rocks lose their magnetization, the Curie depth. A group of depths defines a Curie surface. Depth were evaluated for 13984 locations in the studied area. The Curie surface indicates shallow areas with characteristic linear pattern referred as 'Curie crests', and deep regions representing the magnetic basement for the crust. The surface was compared with geological map and Bouguer map and with the distribution of gold occurrences in the study area. Many of the Curie crests coincide with ancient structural elements containing hydrothermal mineralizations. The Pirineus Megainflection and the Niquelândia Inflection are remarkable features. Parallelism and coincidence with greenstone belts and volcano-sedimentary sequences are clear. The relation with gravity map indicates an ancient suture. Four episodes are suggested to explain the origin of Curie structures: 1) Collision episode, responsible for the geosuture formation; 2) Late erogenic extentional episode, responsible for granitoid and shear zone mineralizations; 3) Sul-Atlantian episode, related with Gondwanaland disruption, and 4) Recent episode, related to E-W regional stresses as the result of South-American plate tectonic. The relationship between gold mineralizations with Curie crests suggest that the former may be a good guide for prospecting in the region.
\end{abstract}

Keywords: Curie depth, aeromagnetic data, geotectonics, gravity, gold deposits.

RESUMO A área de estudo situa-se na região central do Estado de Goiás entre os paralelos $14^{\circ}$ e $16^{\circ} \mathrm{Sul}$ e os meridianos $48^{\circ}$ e $51^{\circ}$ Oeste e é parte da Província Estrutural Tocantins, de complexa e variada geologia. Diversos levantamentos geofísicos foram realizados na região a partir da década de 70, dentre eles está o Projeto Geofísico Brasil-Canadá que resultou em importante levantamento aeromagnético regional.

Através da interpretação magnética de modelos prismáticos, é possível estimar a profundidade onde as rochas perdem sua magnetização, a profundidade Curie. Um conjunto dessas profundidades fornece uma superfície Curie. Para a área estudada foram estimadas 13984 profundidades.

A superfície Curie da área revelou porções rasas lineares (cristas Curie) e regiões mais profundas que podem representar o embasamento magnético da crosta. A superfície foi comparada com a geologia, mapa Bouguer e a distribuição das ocorrências de ouro na área de estudo.

Muitas das cristas Curie coincidem com elementos estruturais antigos com mineralizações hidrotermais. Dentre os elementos correlacionados com as cristas destacam-se a Megainflexão dos Pirineus e a Inflexão de Niquelândia. Notou-se paralelismo e coincidência das cristas com greenstone belts e seqüências vulcano-sedimentares. A relação com o mapa Bouguer revela a presença, ainda marcada, da geossutura brasiliana.

Sugere-se a ocorrência de quatro episódios para explicar a origem das estruturas Curie: 1) Episódio colisional, que gerou a geossutura; 2) Episódio extensional pós-orogênico, responsável pela intrusão de granitóides e formação de mineralizações em zonas de cisalhamento; 3) Episódio Sul-Atlantiano, relacionado ao evento de desmembramento do supercontinente de Gondwana, e 4) Episódio recente, relativo as tensões regionais E-W resultantes do deslocamento da Placa Sul-Americana com reativação de alguns elementos estruturais.

A correlação entre sítios mineralizados e as cristas Curie sugere que as últimas podem ser um guia prospectivo para a região.

Palavras-chaves: profundidade Curie, dados aeromagnéticos, geotectônica, gravimetria, depósitos de ouro

INTRODUÇÃO A região central de Goiás tem despertado interesse desde o século XVIII, quando da descoberta de ouro no sertão goiano pelos bandeirantes. O interesse pela região não é só econômico. Nas últimas décadas, sua complexidade geológica tem atraído diversos pesquisadores.

Com o advento de projetos geofísicos, o interesse pela região aumentou. O Projeto Geofísico Brasil-Canadá (PGBC) realizado na década de 70 , por exemplo, tem sido utilizado até os dias de hoje em pesquisas geológicas e prospectivas. Dentre os principais produtos do PGBC está um importante levantamento aeromagnético.

Com os dados aeromagnéticos é possível estimar as dimensões de corpos magnetizados. Como a temperatura aumenta com a profundidade, a crosta perde as suas propriedades magnéticas a uma certa temperatura, o que permite estimar a profundidade onde este fenômeno ocorre. Essa profundidade é chamada de profundidade do ponto Curie. Estimando-se profundidade Curie em diversos locais pode-se obter uma superficie Curie, a qual configura embasamento magnético da crosta.

Este artigo visa descrever os resultados do emprego de um modelo matemático baseado na distribuição uniforme de um conjunto de corpos prismáticos para estimar a superfície Curie de uma área entre os paralelos $14^{\circ}$ e $16^{\circ} \mathrm{Sul}$ e os meridianos $48^{\circ}$ e $51^{\circ}$ Oeste, correlacioná-la o com mapa geológico regional, levantamentos gravimétricos e a distribuição das ocorrências auríferas, e discutir as suas possíveis implicações tectônicas e de prospecção mineral na região.

REVISÃO GEOLÓGICA A área estudada situa-se no contexto da Província Tocantins, definida por Almeida et al. (1981) como uma região situada entre os crátons do São Francisco, a leste, e o Amazônico, a oeste, e limitada, ao norte e ao sul, pelas bacias sedimentares do Parnaíba e Paraná, respectivamente, e sendo composta de faixas dobradas (Brasília, Paraguai e Araguaia) e um maciço mediano (Fig. 1). A área em questão abrange terrenos pertencentes ao Maciço de Goiás, a Faixa Brasília e a Faixa Araguaia (Figs, 1 e 2).

Maciço de Goiás O Maciço de Goiás, situado na porção central da Província Tocantins, foi identificado por Almeida (1967) como um segmento crustal que teria atuado como pós-país com geossinclínios laterais representados pelas faixas Brasília e Araguaia. Posteriormente, Marini et al (1984) definiram o maciço como um alto do embasamento que teria recebido pouca cobertura sedimentar afetada, jun- 


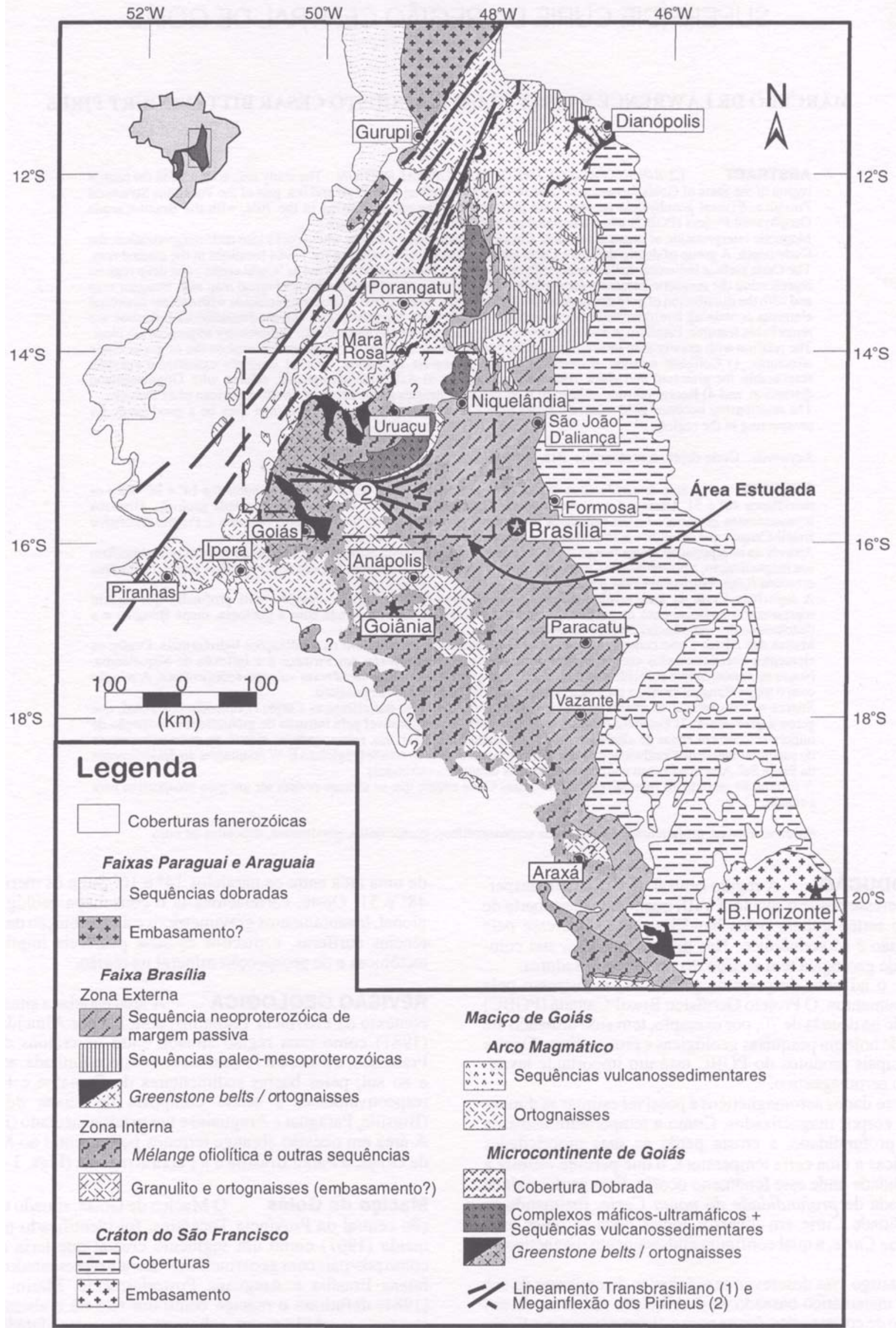

Figura 1 - Mapa geológico da Província Tocantins (modificado de Marini et al. 1984, Fuck et al. 1993, Fuck 1994). Figure 1 - Geologic map of the Tocantins Province (modified from Marini et al. 1984, Fuck et al. 1993, Fuck 1994). 


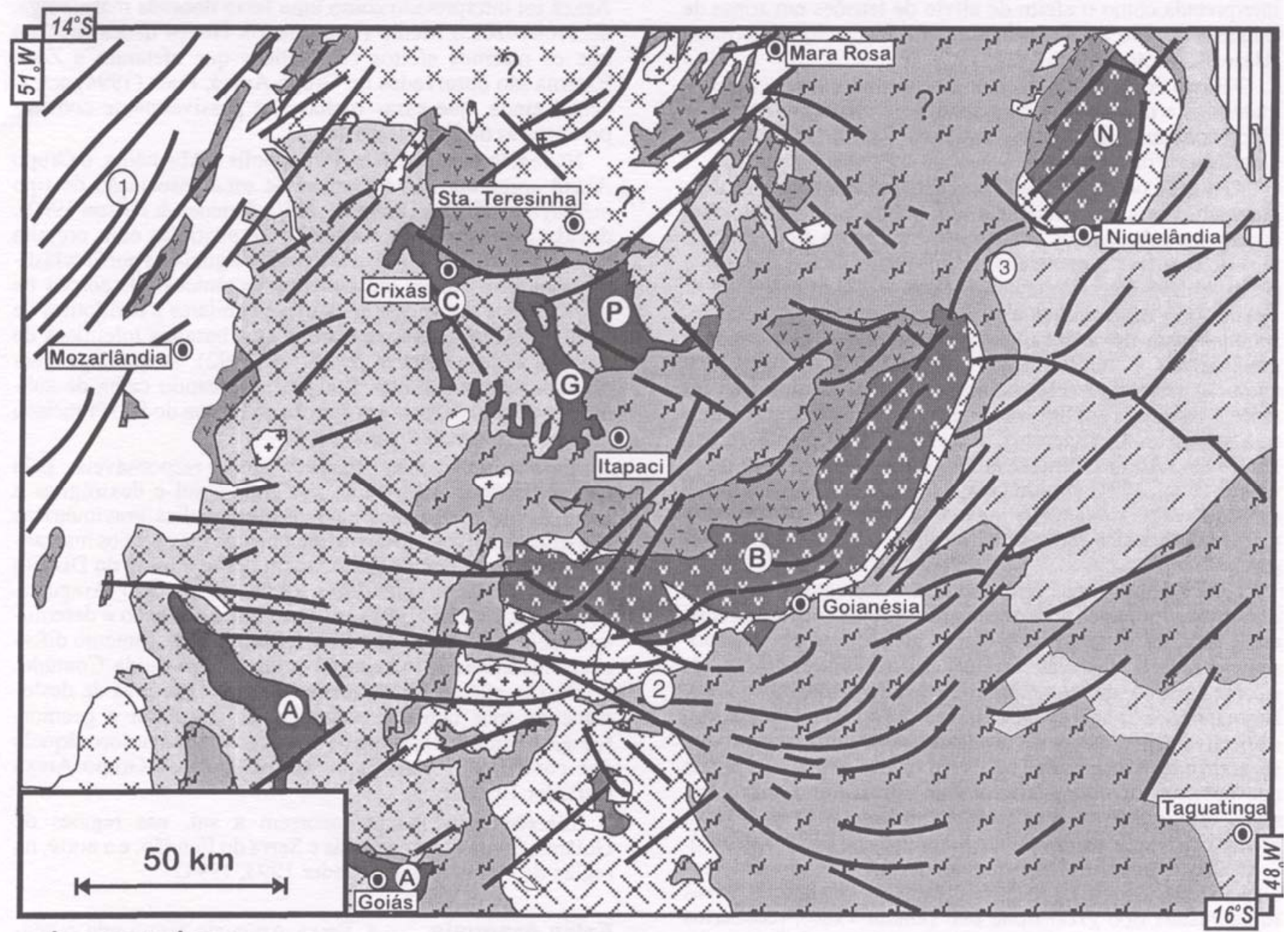

\section{Legenda}

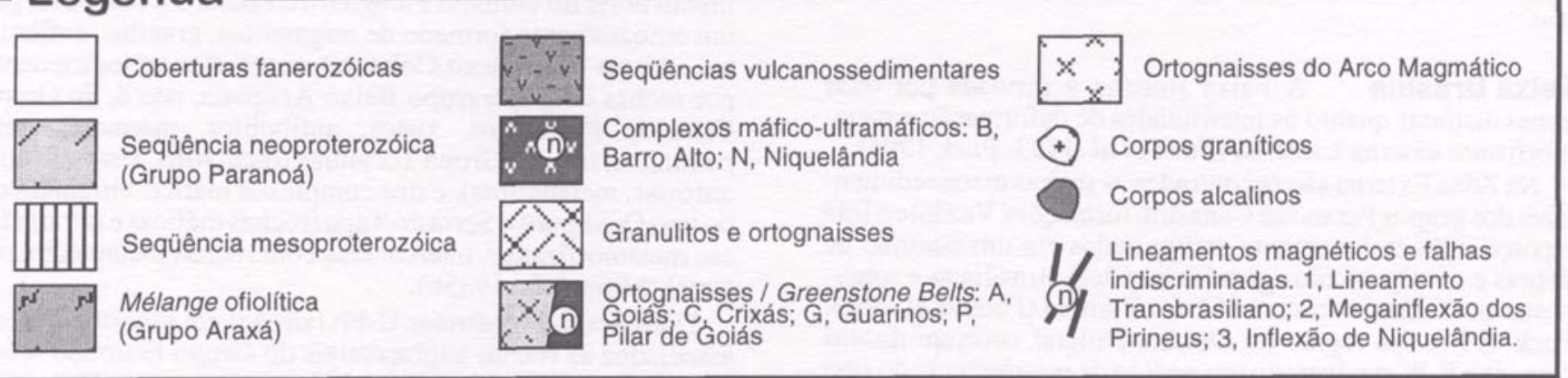

Figura 2 - Mapa geológico da área estudada (modificado de Blum 1995).

Figure 2 - Geologic map of the studied area (modified from Blum 1995).

tamente com o embasamento, por dobramentos, metamorfismo e intrusões sintectônicas durante os ciclos Uruaçuano e Brasiliano.

Posteriormente, Hasui \& Haralyi (1985) compartimentaram a região em três blocos crustais denominados de Araguacema, Porangatu e Brasília.

O bloco Araguacema é limitado a oeste por rochas metavulcano-sedimentares da Faixa Araguaia (Montaivão 1985a, Costa et al. 1988a). O embasamento desse bloco é constituído de xistos, quartzitos e principalmente gnaisses graníticos a tonalíticos. Sobreposto a esse embasamento está a seqüência vulcano-sedimentar do Rio do Coco (Barreira \& Dardenne 1981).

O limite do Bloco Araguacema com o Bloco Porangatu é o Lineamento Transbrasiliano, uma zona de sutura marcada por falhas com direção geral N30E (Marini et al. 1984; Costa et al 1988b). Costa \& Hasui (1988) interpretaram o lineamento como zonas de cisalhamento transcorrente sinistrai de caráter dúctil. Os autores, pelo método $\mathrm{Rb}-\mathrm{Sr}$, obtiveram idades de 2.050/2.217 Ma para amostras de gnaisses da zona de cisalhamento e $1.873 \pm 25 \mathrm{Ma}$ para granitos intrusivos, indicando que o Lineamento Transbrasiliano é mais antigo do que o Ciclo Brasiliano. Os autores ainda encontraram manifestações transcorrentes rúpteis NE dextrais, e NW sinistrais, podendo indicar regime de deformação coaxial com compressão principal E-W. Contudo, um maior desenvolvimento das falhas NE e sua assimetria com as falhas NW indicam deformação binaria dextral. No contexto atual, o Lineamento Transbrasiliano é uma importante faixa sismogênica (Hasui \& Ponçano 1978, Assumpção et al. 1986), 
interpretada como o efeito de alívio de tensões em zonas de fraqueza devido ao deslocamento da Placa Sul-Americana (Hasui \& Mioto 1988).

O Bloco Porangatu é formado em sua maioria por gnaisses, granulitos e raros xistos intercalados de quartzitos. A sul, o bloco contem os greenstone belts das Faixas Goiás, Crixás, Guarinos e Pilar de Goiás.

Na porção oeste, o Bloco Porangatu contém rochas de arco magmático em conseqüência da subducção de litosfera oceânica e subseqüente colisão entre o Cráton Amazônico e uma placa menor representada pelo Maciço de Goiás durante o Neoproterozóico (Pimentel \& Fuck 1987). Kuyumjian \& Dias (1991) sugerem que a evolução do arco magmático foi acompanhada de acresção, envolvendo o arco - retro-arco proterozóico e micro-placas continentais arqueanas. Tal evolução teria sido responsável pela atual estruturação do maciço (estrutura em flor) resultante de evolução tectônica do tipo pop-up (como sugerem Costa et al. 1987) durante o Ciclo Brasiliano (Araújo Filho \& Kuyumjian 1992). O arco magmático (Fuck 1994) compreende os terrenos ortognaissicos e as seqüências vulcano-sedimentares neoproterozóicas das regiões de Sanclerlândia-Bom Jardim, Mara Rosa e Porangatu.

O microcontinente corresponde aos terrenos granitóidegreenstone formados no arqueano juntamente com os terrenos ortognaissicos paleoproterozóicos, as seqüências vulcanosedimentares de Juscelândia, Coitezeiro e Palmeirópolis, adjacentes aos complexos máfico-ultramáficos de Barro Alto, Niquelândia e Canabrava. Os limites ocidental e oriental são, respectivamente, zonas de cisalhamento transpressional que separam o arco magmático neoproterozóico e rampas frontais que colocam os complexos máfico-ultramáficos sobre terrenos ortognaissicos (Fuck 1994) juntamente com a faixa granulítica (limite entre o Bloco Porangatu e o Bloco Brasília).

O Bloco Brasília é constituído de um embasamento arqueano formado principalmente por gnaisses e algumas faixas supracrustais tipo greenstone belt (Danni 1988), recobertos por rochas metassedimentares relacionados ao Ciclo Brasiliano.

Faixa Brasília A Faixa Brasília é formada por duas zonas distintas quanto às intensidades de deformação e metamorfismo: externa e interna (Fuck et al. 1993, Fuck 1994).

Na Zona Externa são encontrados as rochas metassedimentares dos grupos Paranoá e Canastra, formações Vazante e Ibiá e porções do embasamento, estruturados em um cinturão de dobras e cavalgamentos geradas no Ciclo Brasiliano e sobrepostas por falhas inversas ao Grupo Bambuí (Fuck et al. 1993, Fuck 1994). Na região do Distrito Federal ocorrem dobras com eixo E-W produzindo um padrão de interferência do tipo domo-e-bacia com dobras de eixo NS, sugerindo dois episódios deformacionais (Araújo Filho \& Faria 1992). São dobras flexurais de deslizamento com zonas de cisalhamento rúptil e interferência com sistemas transcorrentes, responsáveis por intensa deformação e complexo arranjo geométrico (Fonseca \& Dardenne 1994).

O limite Ocidental da Zona Externa, nas porções norte e central, é marcado por zonas de cisalhamento que sobrepõem os complexos máfico-ultramáficos a granito-gnaisses milonitizados, que, por sua vez, estão sobrepostos ao Grupo Paranoá (Fuck 1994).

O segmento meridional da Zona Externa é caracterizado por extensas descontinuidades tectônicas longitudinais com vergência para o Cráton do São Francisco. O limite oeste, nesta porção, é coincidente com as nappes e empurrões que colocaram o Grupo Araxá sobre a Formação Ibiá e o Grupo Canastra.

A Zona Interna é caracterizada por micaxistos do Grupo Araxá e a pequenas exposições do embasamento. O Grupo
Araxá foi interpretado como uma faixa dobrada mais antiga, do Proterozóico Médio (Uruaçuano). Novos dados revelam que os mesmos efeitos cinemáticos que afetaram a Zona Externa são observados no Grupo Araxá. Fuck (1994) acrescenta, ainda, que essas rochas são possivelmente contemporâneas às da Zona Externa.

Na região de Goianésia, Pirenópolis e Abadiânia, o Grupo Araxá apresenta características de uma associação do tipo melange ofiolítica (Drake Jr. 1980, Strieder \& Nilson 1992), devido à presença de corpos de serpentinito com cromita podiforme, corpos máficos alongados e gnaisses porfiroclásticos bandados, todos em contatos tectônicos. Os corpos de serpentinitos são geoquimicamente similares a peridotitos de manto residual e as rochas máficas a basaltos toleiíticos de arco de ilhas (Strieder \& Nilson 1992). A melange gera pronunciadas anomalias Bouguer, indicando calha de subducção com transporte em direção ao Cráton do São Francisco durante o Neoproterozóico.

Importantes zonas transcorrentes responsáveis pela megainflexão dos Pirineus, levógiras a sul e dextrógiras a norte, também se relacionam com anomalias gravimétricas (Strieder \& Nilson 1992) e a lineamentos magnéticos marcantes. Esses lineamentos se estendem desde o oeste do Distrito Federal até as proximidades da bacia do Rio Araguaia. Strieder \& Nilson (1992) sugerem que a inflexão é determinada pela articulação de várias falhas de deslocamento diferencial resultante de indentação de uma cunha rígida. Contudo, a inflexão não se limita apenas a essas estruturas de deslocamento, mas também está marcada estrutural e geomorfologicamente por lâminas de cavalgamento superiores àquela que contém as rochas metassedimentares do Grupo Araxá (Strieder 1993).

Inflexões semelhantes ocorrem a sul, nas regiões de Goiânia, Santa Cruz de Goiás e Serra do Fundão, e a norte, na região de Niquelândia (Strieder 1993, 1994).

Faixa Araguaia A Faixa Araguaia representa o segmento norte do cinturão Paraguai-Âraguaia e é composta por um embasamento formado de migmatitos, granitos, anfibolitos e xistos (Complexo Colmeia), recobertos tectonicamente por rochas do Supergrupo Baixo Araguaia, isto é, do Grupo Estrondo (quartzitos, xistos, anfibolitos, mármores, serpentinitos, filitos), Grupo Tocantins (quartzitos, xistos, filitos, ardósias, metabasitos), e dos complexos máfico-ultramáficos do tipo Quatipuru e Serra do Tapa (rochas máficas e ultramáficas metamorfizadas, intercaladas com rochas metassedimentares) (Montalvão 1985b).

Datações radiométricas U-Pb (zircão) em granitos e veios associados às rochas supracrustais do Grupo Estrondo revelam idades entre 500 e 580 Ma juntamente com idades arqueanas do embasamento (Moura \& Gaudette 1992). Esses resultados mostram que o maior evento deformacional na Faixa Araguaia tomou lugar há aproximadamente 500 Ma e reforçam a interpretação de uma idade Brasiliana para a evolução estrutural deste cinturão.

As relações da Faixa Araguaia com o Maciço de Goiás são de cavalgamento, com vergência de SSE para NNW, em direção ao Cráton Amazônico (Costa et al. 1988a).

Aluviões cenozóicos da Formação Araguaia obliteram boa parte da faixa homônima. Essa formação contém basicamente sedimentos elásticos da bacia do Rio Araguaia (Marini et al,1984).

Enxames de diques básicos são comuns na área estudada, alguns relacionados ao evento de abertura do Oceano Atlântico (evento Sul-Atlantiano). Os diques intrudem principalmente nos terrenos ortognaissicos e granulíticos (DNPM 1987a), a maioria originando lineamentos magnéticos, principalmente na região da megainflexão dos Pirineus. 
DADOS AEROMAGNÉTICOS Em meados da década de 1970, foi realizado um acordo entre o Ministério das Minas e Energia do Brasil (MME) e a Agência Canadense para o Desenvolvimento Internacional (Canadian International Development Agency - CIDA) para a execução de um levantamento dos recursos minerais da região Centro-Oeste do Brasil. Deste acordo nasceu o Projeto Geofísico Brasil-Canadá (PGBC) (Carmo 1978).

$\mathrm{O}$ projeto cobriu a área situada entre as latitudes $5^{\circ}$ e $16^{\circ}$ Sul e os meridianos $48^{\circ}$ e $51^{\circ}$ Oeste, e objetivou analisar, a curto prazo, o potencial econômico-mineral da área selecionada, usando integração de métodos de pesquisa; definir a evolução geológica do centro-oeste brasileiro, em especial o Vale do Araguaia; e treinamento em técnicas geofísicas e geoquímicas (DNPM 1981).

Do projeto resultou um levantamento aerogeofísico (magnetometria e radiometria) da área do PGBC e levantamentos geoquímicos regionais, eletromagnéticos (INPUT) e magnetometria terrestre em áreas selecionadas (Carmo 1978).

O levantamento foi dividido em três blocos e duas fases de trabalho. A Fase I constituiu-se de levantamento aeromagnetométrico e radiométrico de toda a área, com linhas espaçadas de $2 \mathrm{~km}$ na direção N-S verdadeira e linhas de controle espaçadas em $14 \mathrm{~km}$ na direção E-W. A altura de vôo foi de $150 \mathrm{~m}$. A Fase II foi um levantamento aéreo de semidetalhe, segundo linhas espaçadas de $1 \mathrm{~km}(\mathrm{~N}-\mathrm{S})$, cobrindo as áreas anômalas reveladas pela Fase I e corresponde a 30\% da área total.

Para a aquisição dos dados magnéticos foi utilizado um magnetômetro de campo total do tipo fluxgate, montado em um esporão compensado eletronicamente, com medidas aproximadamente a cada 60 metros e acuracidade de 1 nTesla. Os dados radiométricos foram adquiridos com um espectrômetro diferencial de 4 canais, termicamente estabilizado. A velocidade de vôo foi de aproximadamente $220 \mathrm{~km} / \mathrm{h}$. O controle da altura de vôo foi feito com um radar altímetro de leituras de 1 segundo. A navegação foi controlada por um de sistema Doppler e por fotografias colhidas durante o vôo, com cameras $35 \mathrm{~mm}$ (DNPM 1981).

Os dados de campo foram processados digitalmente no Canadá. No processamento dos dados magnéticos foram utilizadas as linhas transversais (E-W) para ajuste de nível. $\mathrm{O}$ ajuste foi feito mediante a diferença de medidas nas interseções dessas linhas com as linhas N-S. Os dados foram transformados em malha regular, resultando em um conjunto de mapas de contorno de campo magnético total e radiometria, nas escalas 1:100.000 e 1:250.000 (DNPM 1981). Os dados originais e corrigidos estão disponíveis em fitas magnéticas sob a guarda da CPRM.

No presente estudo foram utilizados apenas os dados aeromagnéticos da porção sul do PGBC. Os dados foram transformados em malha regular com célula quadrada de $1 \mathrm{~km}$ usando o método Kriging (Davis 1986) seguido da retirada do valor do International Geomagnetic Reference Field (IGRF) para 1975.

TEMPERATURA CURIE A distribuição de temperatura e pressão na litosfera terrestre afeta uma grande variedade de propriedades das rochas e processos físicos. As propriedades magnéticas das rochas são afetadas ao ponto de, a alguma profundidade na litosfera, a temperatura atinge um valor que provoca a desmagnetiźação. Essa temperatura é conhecida como o Ponto Curie. É possível estimar a profundidade do Ponto Curie através do tratamento de dados magnéticos, com base em certas suposições.

Quando uma temperatura TC é atingida e ultrapassada, o material perde a magnetização. A temperatura TC é chamada de Temperatura Curie. Cada mineral magnético possui TC característica de acordo com sua composição. Para a magnetita pura a Temperatura Curie é de $580^{\circ} \mathrm{C}$ (Nagata 1961).

Vacquier \& Affleck (1941) foram os primeiros a sugerirem que a profundidade do Ponto Curie pode ser estimada pela interpretação magnética de modelos prismáticos, seguidos de Searson \& Hannaford (1957), Alldredge \& Van Voorhis (1961) e Bhattacharyya \& Morley (1965).

A determinação espacial de várias profundidades Curie em uma região permite o traçado de um mapa de isoterma Curie ou superficie Curie. O termo isoterma é desaconselhável, pois implica em uma mesma Temperatura Curie para a região, o que não é verdade, pois minerais diferentes possuem diferentes temperaturas de desmagnetização e a crosta continental não é uniforme. Por isto o termo preferível é superficie.

Uma superfície Curie pode indicar diversas feições na litosfera, tais como (i) mudança composicional vertical da crosta ou limite entre a crosta média e a inferior (Bulina 1961, Hall 1968, Gasparini et al. 1979, Hall et al. 1985); (ii) a interface entre a crosta e o manto; (iii) variações laterais de composição da crosta (Arkani-Hamed \& Strangway 1985); ou (iv) simplesmente o relevo do embasamento magnético. Cada interpretação depende da complexidade geológica da área estudada, da forma como os dados magnéticos foram coletados (levantamento terrestre, marinho, aéreo ou orbital) e da técnica do tratamento dos dados.

Em geral, a determinação da superfície Curie é feita por tentativa-e-erro, cujo resultado é comumente comparado com outro tipo de informação como, por exemplo, dados sísmicos (Hall 1974, Mayhew et al 1982,1985a, Frey 1985,Schnetzler 1985), anomalias gravimétricas (Mayhew et al. 1982, 1985a, Okubo et al. 1985), medidas de fluxo térmico (Shuey et al. 1973, Gasparini et al. 1979, Okubo et al. 1985, Tselentis 1991, Agrawal et al. 1992), medidas de intensidade magnética em rochas expostas (Coles \& Currie 1977, Krutikhovskaya \& Pashkevich 1977, 1979).

A Tabela 1 mostra várias estimativas de profundidade Curie inferidas a partir de anomalias magnéticas em diversas partes do mundo (Mayhew et al. 1985b, Shive et al. 1992).

METODOLOGIA O modelo matemático aqui utilizado é baseado na distribuição uniforme de um conjunto de corpos prismáticos retangulares supondo magnetização constante e utiliza análise espectral, como sugerido por Spector \& Grant (1970). Os autores desenvolveram conceitos muito úteis para a interpretação de dados aeromagnéticos, onde parâmetros tais como tamanho horizontal e espessura de corpos são obtidos por meio do formato observado em espectros radiais. A forma do espectro (Fig. 3), em coordenadas polares $(s, \psi)$ no campo da freqüência, é expressa por (Okubo et al. 1985):

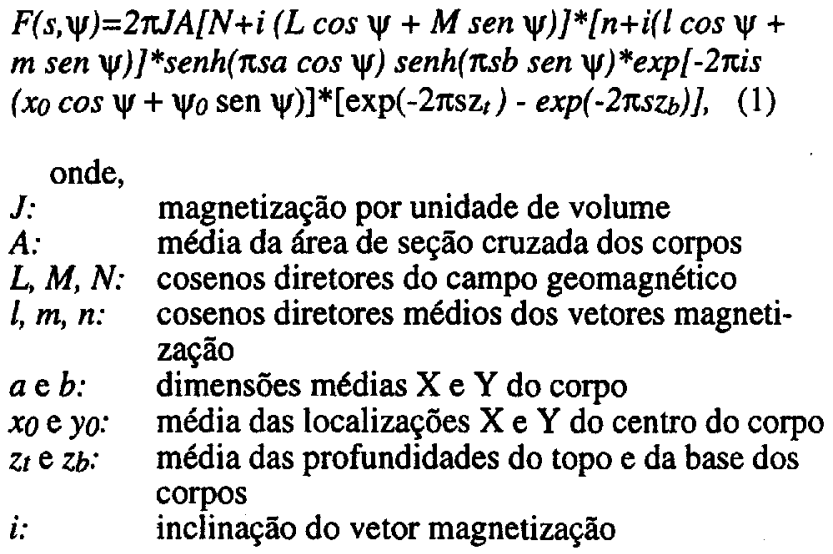

e onde, $\operatorname{senh}(x)=(\operatorname{sen}(x) / x)($ seno hiperbólico), 
Tabela 1 - Espessura da crosta magnética inferida a partir de anomalias magnéticas.

Table 1 - Magnetic crust thickness inferred from magnetic anomalies.

\begin{tabular}{|c|c|c|c|c|}
\hline Local & TD & $\mathbf{H}$ & Causa & Referência \\
\hline Alpha Ridge & $\mathbf{S}$ & 30 & crosta continental cercada por crosta oceânica & Taylor (1983) \\
\hline Arco das Aleutas & S & 7 & lasca subductante & Clark et al. (1985) \\
\hline Arco vulcânico japonês & A & 30 & cinturão vulcânico-plutônico cretácico & Segawa \& Oshima (1975) \\
\hline Arizona & A & $3-30$ & fusão parcial em profundidade no manto superior & Byerly \& Stolt (1977) \\
\hline Bacias do Pacífico e Atlântico & $\mathrm{B}, \mathrm{S}$ & 1 & $\begin{array}{l}\text { expansão do assoalho oceânico, decaimento de TRM (magnetização } \\
\text { remanescente térmica), crescimento de CRM (magnetização } \\
\text { remanescente química) e reversões do campo geomagnético }\end{array}$ & Raymond \& LaBrecque (1987) \\
\hline Broken Ridge & S & 17 & alta VRM (magnetização remanescente viscosa) em crosta espessa & Johnson (1985) \\
\hline Columbia Britânica & A & $30-40$ & isoterma Curie relacionada a subducção & Coles \& Currie (1977) \\
\hline Columbia Britânica & A & & efeito do limite oeste do escudo canadense & Coles (1976) \\
\hline Deccan, Índia & $S$ & $40 \pm 4$ & profundidade do Moho & Agrawal et al. (1992) \\
\hline Escudos báltico e ucraniano & A & $40-50$ & ondulações na base da crosta inferior & $\begin{array}{l}\text { Krutikhovskaya \& Pashkevich } \\
(1977,1979)\end{array}$ \\
\hline EUA contérminos & S & $20-55$ & relevo da base da crosta e variações laterais & Schnetzler (1985) \\
\hline Fennoscandia & C & & ondulaçōes da isoterma Curie & Elming \& Törne (1976) \\
\hline Grécia & A & $10-20$ & arco vulcânico helênico e litosfera africana & Tselentis (1991) \\
\hline Índia & $S$ & $38-68$ & heterogeneidades no manto superior em larga escala & Negi et al. (1987) \\
\hline Kentucky & A, S & 40 & complexo máfico intrusivo atravessando a crosta & Mayhew et al. (1982 1985a) \\
\hline Kyushu, Japão & A & $6,5-12$ & fontes termais & Okubo et al. (1985) \\
\hline Lord Howe Rise & $S$ & & crosta inferior alterada & Frey (1985) \\
\hline Manitoba e Ontario & A & 40 & estrutura na crosta inferior & Hall (1974) \\
\hline Nevada & A & $5-30$ & zona de rift ativo & Blakely (1988) \\
\hline Noroeste da Alemanha & A & várias & relevo do topo da crosta inferior & Hahn et al. (1976) \\
\hline Norte da California & A & $8-12$ & rochas antigas e possível intrusão & Xia (1986) \\
\hline Oregon & A & $6-14$ & ocorrência de corpos com dimensø̃es horizontais & Connard et al. (1983) \\
\hline Pacífico Oeste & B & 15 & ondulaçōes da crosta & LaBrecque et al. (1985) \\
\hline República Centro-Africana & S, A & 35 & plutões máficos & Regan \& Marsh (1982) \\
\hline Sudeste de Minas Gerais & A & $22-27$ & variação vertical na composição da crosta & Gasparini et al. (1979) \\
\hline Sudeste dos EUA & $S$ & 45 & variações composicionais da crosta inferior & Ruder \& Alexander (1986) \\
\hline Suécia & A & $10-23$ & complexo granítico anorogênico & Riddihough (1972) \\
\hline Territ6rios do Noroeste & A & 16 & rochas vulcânicas pré-cambrianas & Coles (1976) \\
\hline Uinta Basin & A & $15-31$ & base da crosta magnética & Shuey et al. (1977) \\
\hline Utah & A & 20-35 & ondulaçōes da isoterma Curie & Shuey et al. (1973) \\
\hline Utah High Plateaus & A & $16-20$ & base da crosta magnética & Shuey et al. (1977) \\
\hline Yellowstone National Park & A & $11-12,5$ & isoterma Curie & Bhattacharyya \& Leu (1975) \\
\hline Yellowstone National Park & A & $7-17$ & base da crosta magnética & Shuey et al, (1977) \\
\hline
\end{tabular}

TD: tipo de dados; A - aeromagnéticos; B - magnetométricos de bordo; C - magnetométricos de campo; S - satélite magnético; H: espessura em km.

$s=\left(u^{2}+y^{2}\right)^{1 / 2}$ (tamanho do vetor frequiência), $\psi=\tan ^{-1}(u / v)$ (direção do vetor frequiência), $\mathrm{u}, \mathrm{v}$ (frequiências espaciais nas direções $\mathrm{X} \mathrm{e}$ $\mathrm{Y}$, respectivamente).

A estimativa da profundidade da base dos corpos pode ser feita em dois passos (Okubo et al. 1985): (i) encontrar a profundidade do centro dos corpos, zo e (ii) determinar a profundidade do topo, $z_{t}$. A profundidade da base do corpo (profundidade Curie estimada) pode ser calculada por:

$$
z b=2 z 0-z t \quad(2)
$$

Para estimar a profundidade do centro do corpo, considerase que o seno hiperbólico na equação (1) a grandes comprimentos de onda tende à unidade, e o espectro passa a ter a seguinte forma:

$$
\begin{aligned}
& F(s, \psi)=4 \pi^{2} V J s[N+i(L \cos \psi+M \operatorname{sen} \psi)] *[n+i(l \cos \psi+ \\
& m \operatorname{sen} \psi)]^{*} \exp \left[-2 \pi \mathrm{is}\left(x_{0} \cos \psi+y_{0} \operatorname{sen} \_\right)\right]^{*} \exp \left(-2 \pi s z_{0}\right),
\end{aligned}
$$

onde $\mathrm{V}$ é o volume médio do corpo. Essa equação pode ser reconhecida como o espectro de um dipolo. Portanto, em frequiências muito baixas, a equação representa uma distribuição aleatória de dipolos pontuais (Okubo et al. 1985). Por mínimos quadrados, a profundidade do centro do corpo pode ser estimada pelo o método de Bhattacharyya \& Leu $(1975,1977)$.
A comprimentos de onda mais curtos, o espectro é dominado pelo sinal do topo dos corpos, permitindo obter a profundidade do topo dos corpos. Isso é possível se consideramos que os senos hiperbólicos da equação (1) tendem à unidade e o último termo exponencial da equação se aproxima de zero. Essas aproximações só fazem sentido se a dimensão vertical do corpo for muito maior do que as horizontais. $\mathrm{O}$ espectro, então, se reduz a:

$F(s, \psi)=2 \pi J A[N+i(L \cos \psi+M \operatorname{sen} \psi)]^{*}[n+i(l \cos \psi+$ $m \operatorname{sen} \psi)]^{*} \exp \left[-2 \pi \operatorname{si}\left(x D_{0} \cos \psi+y_{0} \operatorname{sen} \psi\right)\right]^{*} \exp \left(-2 \pi s z_{t}\right)$. (4)

Essa equação representa, de fato, o espectro de um monopolo (Okubo et al. 1985) e suas semelhanças com a equação (3) levam novamente ao uso do método de Bhattacharyya \& Leu $(1975,1977)$ para estimar a profundidade do topo. Profundidades do topo e do centro do corpo estimadas, resta usar a equação (2) para a encontrar a profundidade da base.

SUPERFÍCIE CURIE DA REGIÃO CENTRAL DE GOIÁS Baseado no método descrito, R.O. Hansen (Okubo et al. 1985) desenvolveu um algoritmo para calcular a profundidade Curie em um ponto. $\mathrm{O}$ algoritmo (a) carrega o arquivo de dados em malha regular, (b) extrai uma janela de dados com o tamanho escolhido, (c) calcula a transformada rápida de Fourier (FFT), (d) calcula o espectro radial para o centro da janela, (e) prepara o espectro para ser visto em programa gráfico, onde serão escolhidas as porções do espec- 
tro que representarão as fontes profundas e as rasas, (f) extrai a porção escolhida do espectro, $(\mathrm{g})$ calcula as profundidades do topo, do centro e da base e (h) salva em arquivo. Para aprimorar o algoritmo, foi acrescentada uma rotina para automatizar os cálculos para vários pontos, mas foi necessário previamente definir as porções apropriadas do espectro e o tamanho ideal da janela de dados.

Para definir as porções apropriadas do espectro, é necessário encontrar, no mesmo, um ponto de inflexão que o divida em duas partes (Fig. 3). A primeira parte, localizada a esquerda do gráfico, representa as fontes mais profundas e é usada para o cálculo da profundidade do centro do corpo. A segunda, a direita do gráfico, representa as fontes mais rasas e é usada para calcular o topo dos modelos prismáticos. Essa escolha é repetida por tentativa-e-erro, empregando diversos tamanhos de janela de dados para um mesmo ponto. $\mathrm{O}$ ponto selecionado para este estudo situa-se próximo à cidade de Niquelândia-GO, onde também existem medidas de fluxo

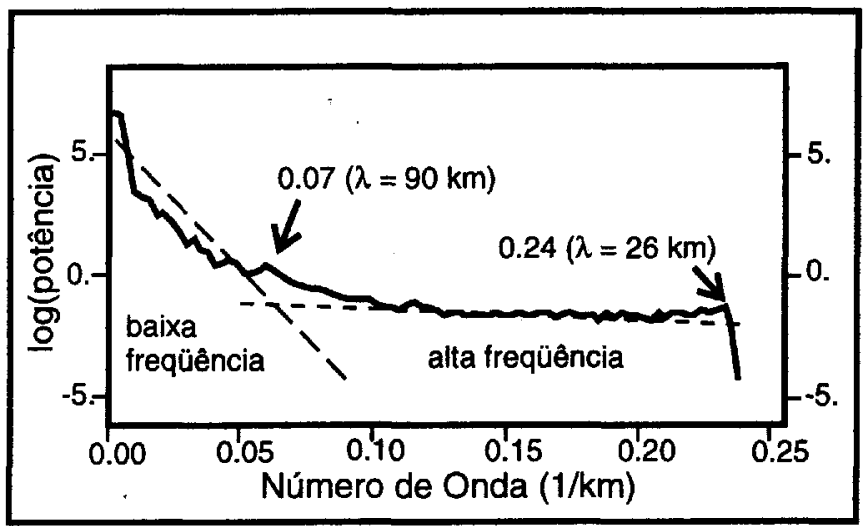

Figura 3 - Espectro radial médio de dados aeromagnéticos da área estudada. Número de onda escolhido: 0,07 rad/km. Figure 3 - Spectrum radialy averaged from aeromegnetic data of the studied area. Wavenumber selected: $0,07 \mathrm{rad} / \mathrm{km}$.

\section{térmico.}

O tamanho da janela de dados é selecionado quando a relação tamanho de janela versus profundidade Curie se torna estável. A Figura 4 mostra que essa relação estabiliza a partir de $26 \mathrm{~km}$ para o tamanho de janela com uma profundidade aproximada de $33 \mathrm{~km}$. Essa profundidade foi calculada usando-se um número de onda de 0,07 radianos por $\mathrm{km}$ como o limite entre as duas porções do espectro (Fig. 3). Isso pode parecer estranho porque, teoricamente, para uma janela de 26 $\mathrm{km}$, é necessário um número de onda da ordem de $0,24 \mathrm{rad} / \mathrm{km}$ ou para um número de onda de $0,07 \mathrm{rad} / \mathrm{km}$, é requerida uma janela de $90 \mathrm{~km}$. Com uma janela menor que $90 \mathrm{~km}$, a superfície Curie aumenta de área ganhando em detalhe, mas perde em qualidade.

Uma vez definidos o número de onda no espectro $\left(7 \times 10^{-5}\right.$ $\mathrm{rad} / \mathrm{m})$ e o tamanho de janela $(26 \mathrm{~km})$, resta aplicar o algoritmo automático. Usando uma cela unitária quadrada de $2 \mathrm{~km}$, estimou-se aproximadamente 14 mil pontos Curie para a maior parte da área de estudo, perdendo apenas $13 \mathrm{~km}$ (tamanho da meia janela) em cada borda. O mapa resultante é mostrado na Figura 5.

DISCUSSÃO E CONCLUSÕES A superfície Curie (Fig. 5) mostra o relevo do embasamento magnético da região central de Goiás, representando níveis crustais inferiores (30-37 km) correspondentes, possivelmente, à interface entre as crostas média e inferior, refletindo mudança composicional vertical nesta interface. Como a profundidade da

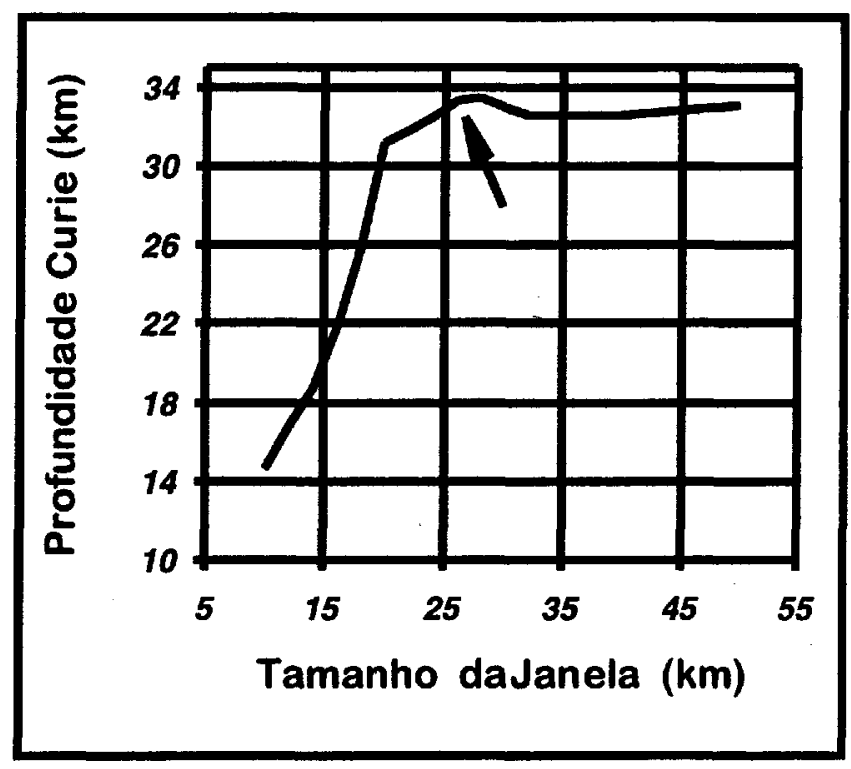

Figura 4 - Relação entre o tamanho da janela de dados e a profundidade Curie. A seta indica a posição onde a relação começa a se estabilizar.

Figure 4 - Relation between window size and Curie depth. The arrow indicates the beginning of the stabilized relation.

descontinuidade de Mohorovicic foi estimada entre 38 e 40 $\mathrm{km}$ para a região (Marangoni 1994), não é descartada a hipótese de que as maiores profundidades Curie $(\sim 37 \mathrm{~km})$ representem esse limite.

A profundidade média da superfície Curie é de 30,8 $\pm 3,4$ $\mathrm{km}$. Quando se compara esse valor com a profundidade média calculada através do fluxo térmico (Tselentis 1991), nota-se uma proximidade muito grande de valores (Tabela 2).

A Figura 5 apresenta uma série de anomalias de baixa profundidade que podem representar a porções onde, provavelmente, as rochas perderam sua magnetização numa temperatura Curie mais baixa. Em contrapartida, nas áreas mais profundas a temperatura de desmagnetização é maior.

Muitas das porções mais rasas apresentam feições lineares, ou cristas Curie. Essa linearidade sugere que essas áreas foram afetadas por um evento termotectônico pretérito que alterou as propriedades magnéticas das rochas. Eventos tectônicos e/ou mudanças na composição podem ou não estar representadas na superfície. Para verificar essas hipóteses, é necessário comparar a superfície Curie com o mapa geológico da região.

A Figura 6 é a sobreposição do mapa geológico com a superfície Curie da região central de Goiás. Nota-se alguma relação entre as cristas Curie e os greenstone belts. Configuração semelhante ocorre no Complexo Niquelândia e na seqüência vulcano-sedimentar adjacente. Essa relação deve ser vista com cuidado, pois na região do Complexo Barro Alto, de origem semelhante à de Niquelândia, o fenômeno não é observado.

Bem mais clara é a coincidência de cristas Curie com a Megainflexão dos Pirineus, o que sugere a sua origem termotectônica.

As relações de idades com a superfície Curie não são claras, pois tanto porções rasas quanto profundas ocorrem indiscriminadamente desde terrenos arqueanos até neoproterozóicos.

Quando se sobrepõe o mapa gravimétrico da região (Marangoni 1994) à superfície Curie (Fig. 7) observa-se algumas relações interessantes, principalmente na porção ocidental do mapa. Nessa área, uma crista Curie (AW) apresenta curvatura semelhante a do forte gradiente Bouguer. Esse gradiente é 


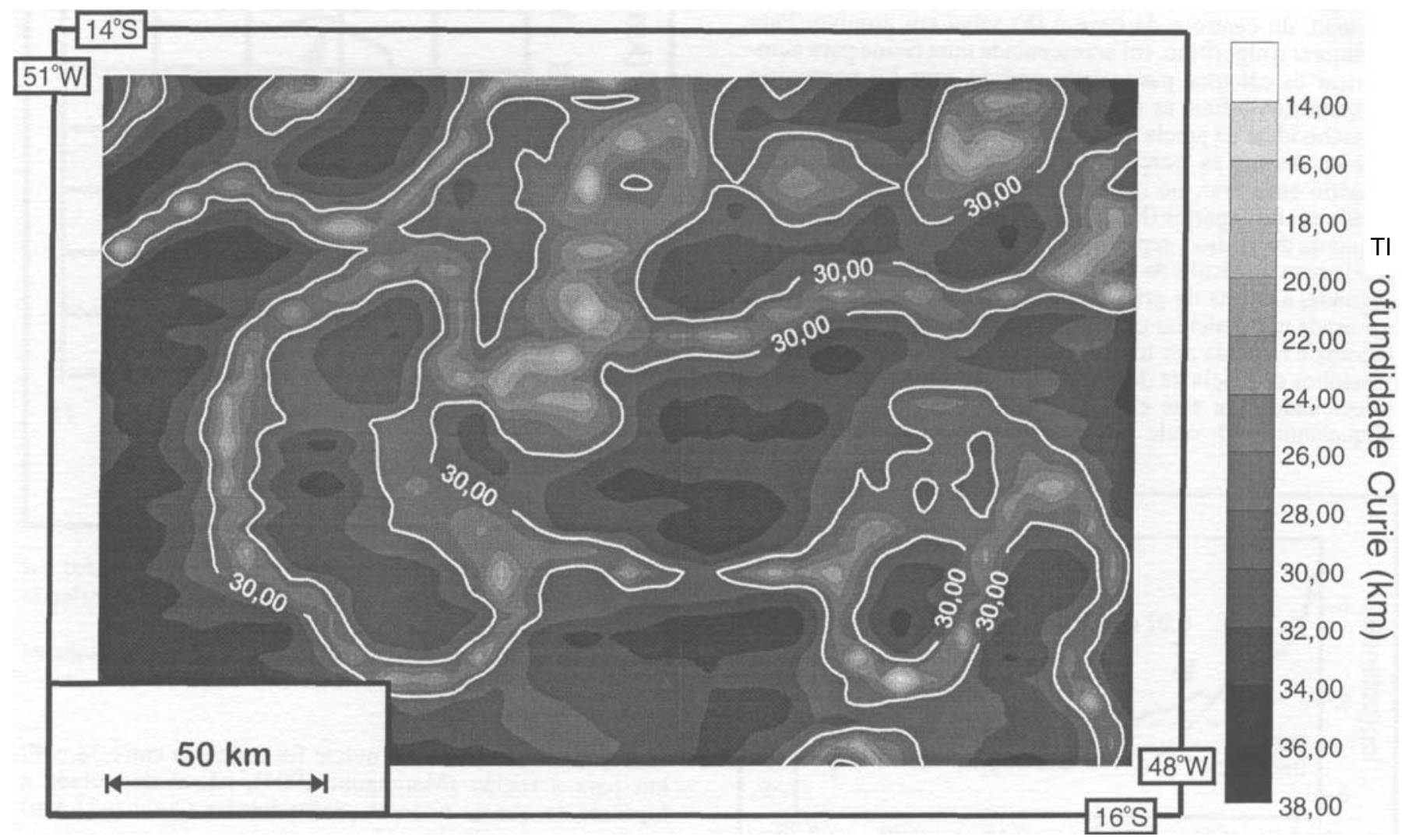

Figura 5 - Superficie Curie da região central de Goiás.

Figure 5 - Curie surface of the central Goiás region.

Tabela 2 - Profundidades Curie estimadas de fluxo térmico e comparação da sua média e com a calculada por dados magnéticos. Table 2 - Curie depths estimated from heat-flow and comparison between its average and the calculated by the average aeromagnetic Curie depths.

\begin{tabular}{|c|c|c|c|c|c|}
\hline Localidade & Latitude & Longitude & $\begin{array}{l}\text { Fluxo térmico } \\
\left(\mathrm{mW} / \mathrm{m}^{2}\right)\left({ }^{1}\right)\end{array}$ & $z=52,5-16,6 Q(m)\left(^{2}\right)$ & $\mathrm{z}_{\mathrm{b}}$ deste estudo $(\mathrm{m})\left({ }^{3}\right)$ \\
\hline Goiás & $15^{\circ} 56^{\prime}$ & $50^{\circ} 07^{\prime}$ & 71,0 & 24.438 & - \\
\hline Americano do Brasil & $16^{\circ} 14^{\prime}$ & $50^{\circ} 05^{\prime}$ & 38,0 & 37.481 & - \\
\hline Niquelândia & $14^{\circ} 13^{\prime}$ & $48^{\circ} 18^{\prime}$ & 63,0 & 27.800 & 33.316 \\
\hline Média & $14^{\circ} 59^{\prime}$ & $49^{\circ} 11^{\prime}$ & $55,0 \pm 14,8$ & $30.762 \pm 5.854$ & - \\
\hline Média da área de estudo $(4)$ & $14^{\circ} 58^{\prime}$ & $49^{\circ} 27^{\prime}$ & . & - & $30.763 \pm 3.372(5)$ \\
\hline
\end{tabular}

considerado por Strieder (1993) como indentação de uma cunha rígida do Cráton do São Francisco com uma porção termalmente abrandada do Cráton Amazônico. Em perfil, o gradiente é comumente associado à zona de sutura continental (Marangoni 1994) entre a Placa do São Francisco (Cráton do São Francisco e áreas marginais) e a Placa do Maciço de Goiás, incluindo a Megainflexão dos Pirineus (MP). Essa associação sugere que a crista $\mathrm{AW}$ representa um limite composicional lateral na crosta, apesar de não ter correspondência em superfície (Fig. 6).

Na região do Complexo Niquelândia (NI), há uma sobreposição de um alto gravimétrico com um alto Curie (Fig. 7). Essa feição não ocorre no Complexo Barro Alto (BA), sugerindo que as feições Curie relacionam-se a fontes diversas e não às rochas desses complexos.
É importante ressaltar que a densidade de dados gravimétricos na área é aproximadamente $10 \mathrm{x}$ menor do que a do mapa Curie $\left(0,018\right.$ contra 0,196 pontos $\left./ \mathrm{km}^{2}\right)$. Levantamento gravimétrico de malha mais densa está sendo realizado nas regiões dos greenstone belts da área.

Como a área de estudo faz parte de importante província mineral (Blum \& Bhaskara Rao 1992), é interessante mostrar a relação entre a superfície Curie e as ocorrências de ouro. A Figura 8, construída a partir de dados de DNPM (1987a, b, c, d, inédito) sobrepostos à superfície Curie, mostra que há uma aparente correlação entre as cristas Curie e zonas de cisalhamento que controlaram a circulação dos fluidos geradores das importantes mineralizações auríferas.

Do exposto, pode-se sugerir quatro episódios possíveis para explicar a origem e evolução da superfície Curie e estruturas associadas: 


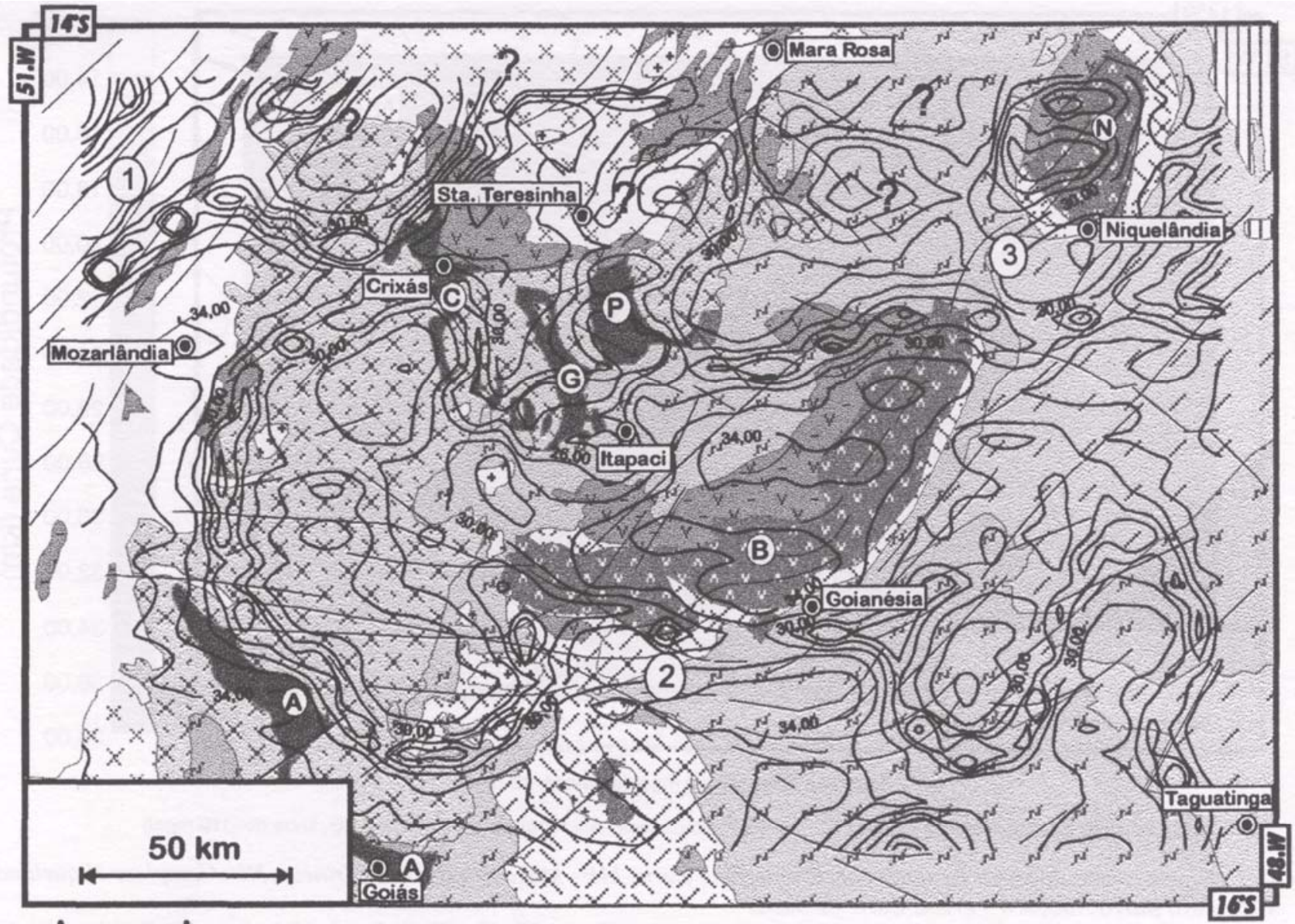

Legenda

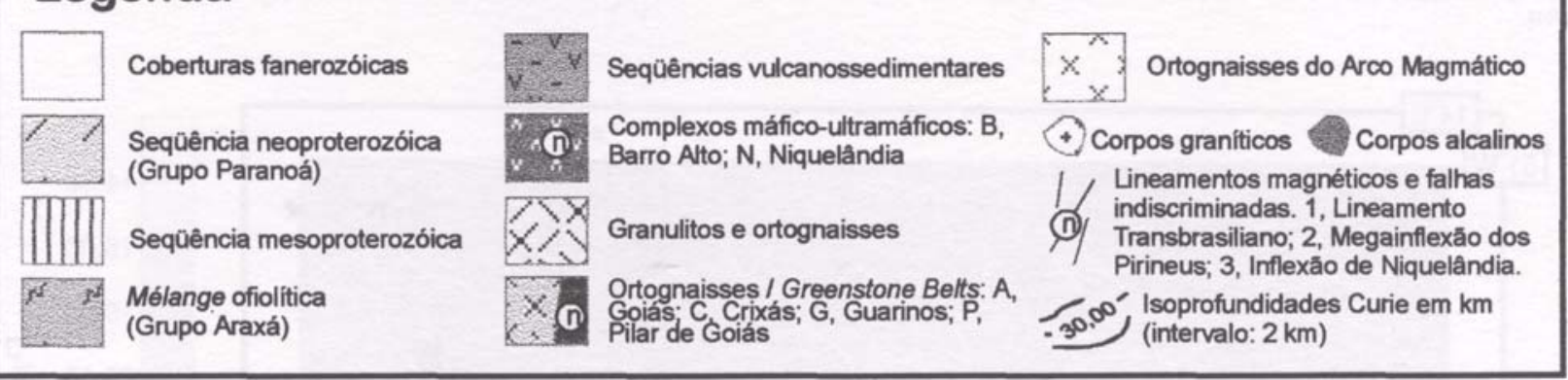

Figura 6 - Mapa geológico da área estudada com superposição da superfície Curie.

Figure 6 - Curie surface superposed to the geologic map of the studied area.

1) Episódio colisional (evento orogênico Brasiliano): é o episódio responsável pela geossutura revelada pelos dados gravimétricos (Marangoni 1994). A superfície Curie provavelmente mostra a sutura através da linha SC da Figura 7, onde se observa suave diminuição de profundidades, coincidente com o limite leste do gradiente gravimétrico (LEG, Fig. 7). Esse limite corresponde à borda leste dos terrenos granulíticos e dos complexos máfico-ultramáficos. Foi nesse episódio que segundo Strieder et al. (1994) se originou o Lineamento Transbrasiliano.

2) Episódio extensional pós-orogênico: este evento ocorreu ao final, ou logo após, a colisão no Ciclo Brasiliano, durante o rápido soerguimento da crosta continental, sugerido por Pimentel (1992), em decorrência da denudação de cadeia orogênica. Neste episódio houve o aproveitamento de estruturas previas, como o Lineamento Transbrasiliano, estruturas transcorrentes como a Megainflexão dos Pirineus e a Inflexão de Niquelândia. $\mathrm{O}$ evento foi responsável pela gênese de granitóides em zonas de cisalhamento, onde a fonte de calor seria continuamente reabastecida pelo movimento, como sugerido por Marshak et al. (1992) e talvez pela entrada de água de supracrustais sobrejacentes (Grupo Araxá ?). Esse sistema seria responsável pela geração de depósitos hidrotermais como sugerem as idades Rb-Sr entre 550 e 430 Ma das rochas hospedeiras das mineralizações de ouro de Crixás (Fortes et al. 1993). Isto também sugere que as mineralizações e as cristas Curie têm idades semelhantes.

3) Episódio Sul-Atlantiano: correspondente à fase inicial de desmembramento do supercontinente de Gondwana e a abertura do oceano Atlântico Sul, responsável também pelos derrames basálticos na Bacia do Paraná e pelo preenchimento de estruturas pretéritas, como da Megainflexão dos Pirineus, por diques básicos no Mesozóico. Não existem diques datados na região, podendo, portanto, estes ser anteriores ao episódio.

4) Episódio recente: este episódio estaria ligado às tensões regionais atuais $(\mathrm{E}-\mathrm{W})$ resultantes da movimentação da Placa 


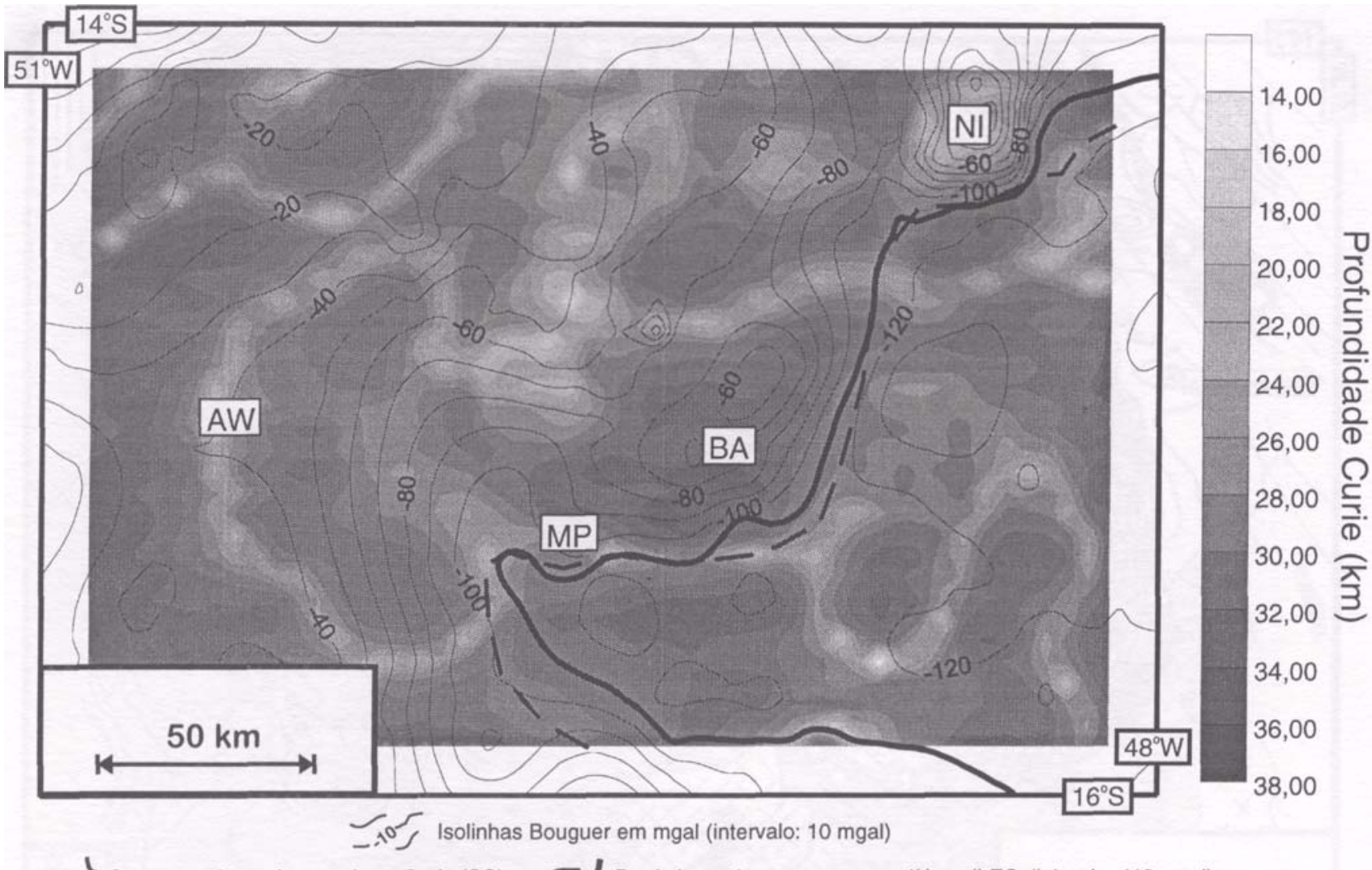

$\lceil$ Sutura continental com cristas Curie (SC) $\checkmark$ Borda leste dos terrenos granulíticos (LEG, linha de -110 mgal)

Figura 7 - Superposição do mapa Bouguer com a superficie Curie. MP - Megainflexão dos Pirineus, NI - Complexo Niquelândia, BA - Complexo Barro Alto, A W - crista Curie de oeste.

Figure 7 - Overlay of the Bouguer map and the Curie surface. MP - Pirineus Megainflection, NI - Niquelândia Complex, BA - Barro Alto Complex, AW - Curie west crest.

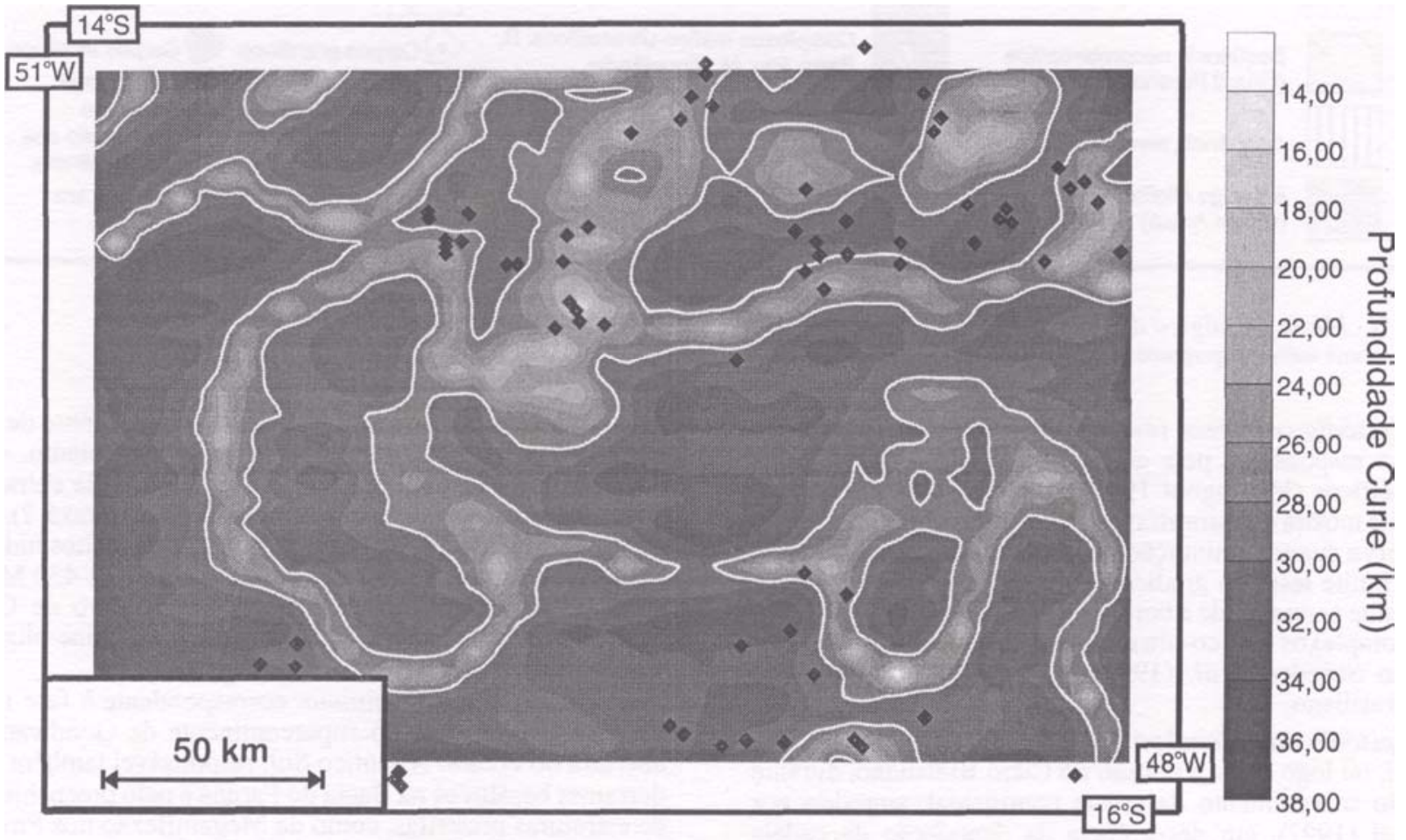

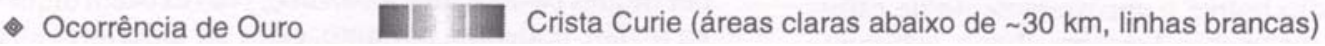

Figura 8 - Mapa de ocorrências de mineralizações de ouro (DNPM. 1987a, b, c, d, inédito) sobreposto ao de superfície Curie. Figure 8 - Overlay of gold occurrences (DNPM, 1987a, b, c, d, unpublished) to Curie surface. 
Sul-Americana (Assumpção et al. 1985), responsáveis pela reativação de antigas estruturas como a Megainflexão dos Pirineus, a Inflexão de Niquelândia e, principalmente, o Lineamento Transbrasiliano que reflete na configuração das cristas Curie.

Aparentemente, a coincidência de cristas Curie com as mineralizações tardi- ou pós-brasilianas se deve à reativação das estruturas ligadas ao segundo episódio. O terceiro episódio, e talvez um ou mais intermediários entre o segundo e o terceiro, merece maior detalhamento, pois, no estágio atual do conhecimento, pouco se sabe a respeito da influência da evolução das bacias paleozóicas na área em questão.
Agradecimentos À CAPES, CNPq, Companhia de Pesquisa de Recursos Minerais (CPRM), Departamento Nacional da Produção Mineral (DNPM), Instituto de Geociências da Universidade de Brasília (IG/UnB), Profs. Maria do Perpétuo Socorro Adsumilli, José Oswaldo de Araújo Filho, Luiz J. H. D'el Rey Silva, Reinhardt A. Fuck, Ariplínio A. Nilson, César F. Ferreira Filho, Marcel A. Dardenne, Paulo R. Menezes e Bhaskara Rao Adsumilli do IG/UnB e aos Profs. Marta S. M. Mantovani, Yara Marangoni e Valiya M. Hamza do IAG/USP.

\section{REFERÊNCIAS}

AGRAWAL, P.K.; THAKUR, N.K. \& NEGI, J.G. 1992. MAGSAT data and Curie-depth below Deccan Flood Basalts (India). PAGEOPH. 138(1):61-75.

ALLDREDGE, L.R. \& VAN VOORHIS, G.D. 1961. Depth to sources of magnetic anomalies. J. Geophys. Res. 66:3793-3800.

ALMEIDA, F.F.M. de 1967. Nota sobre o Pré-Cambriano na região central de Goiás. Bol. Paranaense Geoc. 26:19-22.

ALMEIDA, F.F.M. DE; HASUI, Y.; NEVES, B.B.B. \& FUCK, R.A. 1981. Brazilian structural provinces: an introduction. Earth Sci. Rev. 17:291-317.

ARAÚJO FILHO, J.O. \& FARIA, A. 1992. Características estruturais da propagação do empurrão do Canastra sobre o Paranoá no evento Brasiliano no Distrito Federal. CONOR. BRAS. GEOL., 37. São Paulo 1992. Bol. Res. Exp... São Paulo, SBG. p. 319-320.

ARAÚJO FILHO, J.O. \& KUYUMJIAN, R.M. 1992. Uma hipótese alternativa para a origem e evolução dos terrenos arqueanos e das seqüências vulcano-sedimentares paleoproterozóicas de Goiás. CONOR. BRAS. GEOL., 37. São Paulo 1992. Bol. Res. Exp... São Paulo, SBG. p. 168-169.

ARKANI-HAMED, J. \& STRANGWAY, D.W. 1985. Lateral variations of apparent magnetic susceptibility of lithosphere deduced from Magsat data. J. Geophys. Res. 90:2655-2664.

ASSUMPÇÃO, M.; LIMA, T.M. \& TOMÁS, L.A.R. 1986. O sismo de Araguapaz de 14.01.1986 e o Lineamento Transbrasiliano. CONGR. BRAS. GEOL., 34. Goiânia 1986. Anais... Goiânia, SBG. v. 6. p. 2573-2580.

ASSUMPÇÃO, M.; SUAREZ, G. \& VELOSO, J.A.V. 1985. Fault plane solutions of intraplate earthquakes in Brazil: some constrains on the regional stress field. Tectonophys. 113:283-293.

BARREIRA, C.F. \& DARDENNE, M.A. 1981. A seqüência vulcano sedimentar do Rio do Coco. In: SIMPÓSIO DE GEOLOGIA DO CENTRO-OESTE, 1. Atas... Goiânia, p. 241-264.

BHATTACHARYYA, B.K. \& LEU, L.K. 1975. Analysis of magnetic anomalies over Yellowstone National Park: mapping of Curie-point isothermal surface for geothermal reconnaissance. J. Geophys. Res., 80:4461-4465.

BHATTACHARYYA, B.K. \& LEU, L.K. 1977. Spectral analysis of gravity and magnetic anomalies due to rectangular prismatic bodies. Geophysics, 42:41 -50.

BHATTACHARYYA, B.K. \& MORLEY, L.W. 1965. The delineation of deep crustal magnetig bodies from total field aeromagnetic anomalies. J. Geomag. andGeoelec., 17:237-252.

BLAKELY, R.J. 1988. Curie temperature isotherm analysis and tectonic implications of aeromagnetic data from Nevada. J. Geophys. Res., 93:11817-11832.

BLUM, M.L.B. \& BHASKARA RAO A. 1992. Mapa previsional (preliminar) para ouro no Brasil. In: SEM. PESQUISA DA UNB GRADUAÇÃO E PÓS-GRADUAÇÃO, 2. Brasília 1993. Anais... UnB, Brasília, p. 154-155.

BLUM, M.L.B. 1995. Superfície Curie da Região Central de Goiás e Relações com Geologia, Geotectônica e Recursos Minerais. Brasília. 82 p. (Dissertação de Mestrado, Instituto de Geociências da Universidade de Brasília).

BULINA, L.V. 1961. The use of airborne magnetic prospecting data in deep-seatted structure of the Earth's crust within the Siberian Platform. Sovetskaya Geol. 5:134-138.

BYERLY, P.E. \& STOLT, R.H. 1977. An attempt to define the Curie point isotherm in northern and central Arizona. Geophysics, 42:1394-1400.

CARMO, S.D. 1978. Programação e execução do Projeto Geofísico Brasil-Canadá. In: CONGR. BRÁS. GEOL., 30. Recife 1978. Anais... Recife, SBG. v. 5 p. 2233-2247.
CLARK, S.C.; FREY, H. \& THOMAS, H.H. 1985. Satellite magnetic anomalies over subduction zones: The Aleutian Arc anomaly. Geophys. Res. Lett. 12:41-44.

COLES, R.L. 1976. A flexible interactive magnetic anomaly interpretation technique using multiple rectangular prisms. Geoexploration, 14:125-141.

COLES, R.L. \& CURRIE, R.G. 1977. Magnetic anomalies and rock magnetization in the southern Coast Mountains, British Columbia: possible relation to subduction. Can. J. Earth Sci. 14:1753-1770.

CONNARD, G.; COUCH, R. \& GEMPERLE, M. 1983. Analysis of aeromagnetic measurements from the Cascade Range in central Oregon. Geophysics, 48:376-390.

COSTA, J.B.S. \& HASUI, Y. 1988. Aspecto do Lineamento Transbrasiliano na Região de Porto Nacional -Natividade, GO. In: CONGR. BRAS. GEOL., 35. Belém 1988. Anais... Belém, SBG. v. 5. p. 2208-2216.

COSTA, J.B.S.; HASUI, Y. \& GORAYEB, P.S. 1988a. Relações Estruturais entre a Faixa Araguaia e o Maciço Mediano Goiano na região de Paraíso do Norte-Gurupi, GO. In: CONGR. BRAS. GEOL., 35. Belém 1988. Anais... Belém, SBG. v. 5. p. 2187-2196.

COSTA, J.B.S.; HASUI, Y. \& HARALYI, N.B.E. 1988b. A zona de articulação dos blocos Brasília e Araguacema no Centro-Norte de Goiás. In: CONGR. BRAS. GEOL., 35. Belém 1988. Anais... Belém, SBG. v. 5. p. 2197-2207.

COSTA, J.B.S.; HASUI, Y. \& HARALYI, N.L.E. 1987. The Central Brazil pop-up: an exemple of double ancient oblique continental colision. CONFERENCE OF DEFORMATION AND PLATE TECTONICS, Gijon, Espanha. Abstracts... p. 24-25.

DANNI, J.C.M. 1988. Os Greenstone Belts da Província Tocantins no Estado de Goiás, Brasil. Rev. Bras. Geoc. 18(4):381-390.

DAVIS, J.C. 1986. Statistics and Data Analisys in Geology. 2 ed. New York, Wiley. $646 \mathrm{p}$.

DNPM 1981. Projeto Geofisico Brasil-Canadá: histórico e atividades até 30/09/77. MME/DNPM, Goiânia, GSC, Canadá. 300 p.

DNPM 1987a. Mapa Geológico do Estado de Goiás (Escala 1:1.000.000). Brasília, DNPM/MME.

DNPM 1987b. Projeto Mapas Metalogenélicos e de Previsão de Recursos Minerais, Ceres, Folha SD.22-Z-C (Escala 1:250.000). Brasília, DNPM/MME.

DNPM 1987c. Projeto Mapas Metalogenéticos e de Previsão de Recursos Minerais, Goianésia, Folha SD.22-Z-D (Escala 1:250.000). Brasília, DNPM/MME

DNPM 1987d. Projeto Mapas Metalogenéticos e de Previsão de Recursos Minerais, Uruaçu, Folha SD.22-Z-B (Escala 1:250.000). Brasília, DNPM/MME.

DNPM inédito. Projeto Mapas Metalogenéticos e de Previsão de Recursos Minerais, Mozarlândia, Folha SD.22-Z-A (Escala 1:250.000). Brasília, DNPM/MME.

DRAKE JR., A.A. 1980. The Serra de Caldas Window. Denver, U.S.G.S Prof. Paper 1119:1-11.

ELMING, S.-A. \& TORNE, A. 1976. The blue road geotraverse: A magnetic ground survey and the interpretation of magnetic anomalies. Geol. Foeren. Stockholm Forth., 98:264-270.

FONSECA, M.A. \& DARDENNE, M.A. 1994. Compartimentação estrutural de parte da Zona Externa da Faixa Brasília ao norte da Inflexão dos Pirineus. SIMP. GEOL. CENTRO-OESTE, 4. Brasília 1994. Anais... Brasília, SBG. p. 181-183.

FORTES, P.T.F.O.; PIMENTEL, M.M. \& TEIXEIRA, W. 1993. Geocronologia $\mathrm{Rb}-\mathrm{Sr}$ das rochas encaixantes do depósito aurífero Mina III, Crixás, Goiás. CONGR. BRAS. GEOQ., 4. Brasília 1993. Resumos Expandidos... Brasília, SBGq. p.250-252. 
FREY, H. 1985. Magsat and POGO magnetic anomalies over the Lord Howe Rise: evidence against a simple continental crustal structure. $J$. Geophys Res. 90:2631-2639.

FUCK, R.A. 1994. A Faixa Brasília e a compartimentação tectônica na Província Tocantins. In: SIMP. GEOL. CENTRO-OESTE, 4. Brasília, SEG. Anais... Brasília, p. 184-187.

FUCK, R.A.; JARDIM DE SÁ, E.F.; PIMENTEL, M.M.; DARDENNE, M.A. \& PEDROSA SOARES, A.C. 1993. As faixas de dobramento marginais do Cráton do São Francisco: Síntese dos Conhecimentos. In: DOMINGUEZ, J.M.L. \& MISI, A. ed. O Cráton do São Francisco. Salvador, SBG/SGM/CNPq. p. 161-185.

FURUMOTO, S. 1990. Sistema de banco de dados geotérmicos (SISTERM) para microcomputadores da linha IBM PC/XT/AT. 80p. (Dissertação de Mestrado, Instituto Astronômico e Geofísico da Universidade de São Paulo).

GASPARINI, P.; MANTOVANI, M.S.M.; CORRADO, G. \& RAPOLLA A. 1979. Depth of Curie temperature in continental shields: a compositional boundary?. Nature 278:845-846.

HAHN, A.; KIND, E.G. \& MISHRA, D.C. 1976. Depth estimation of magnetic sources by means of Fourier amplitude spectra. Geophys. Prospect. 24:287-308.

HALL, D.H. 1968. Regional magnetic anomalies, magnetic units, and crustal structure in the Kenora district of Ontario. Can. J. Earth Sci. 5:1277-1296

HALL, D.H. 1974. Long-wavelength aeromagnetic anomalies and deep crustal magnetization in Manitoba and northwestern Ontario, Canada. J. Geophys. 40:403-430.

HALL, D.H.; NOBLE, LA. \& MILLAR, T.W. 1985. Crustal structure of the Churchill-Superior boundary zone between $80^{\circ}$ and $98^{\circ} \mathrm{W}$ longitude from Magsat anomaly maps and stacked passes. J. Geophys. Res. 90:2621-2630.

HASUI, Y \& HARALYI, N.L.E 1985 A megaestruturação de Goiás. In SIMPÓSIO DE GEOLOGIA DO CENTRO-OESTE, 2. Goiânia, Ata.. Goiânia, SBG. p. 120-140.

HASUI, Y. \& MIOTO, J.A. 1988. A Zona Sismogênica de Porangatu (GO). In: CONGR. BRÁS. GEOL., 35. Belém 1988. Anais.. Belém, SBG. v. 5. p. $2173-2186$.

HASUI, Y. \& PONÇANO, W.L. 1978. Geossuturas e sismicidade no Brasil. In: CONGR. BRAS. GEOL. ENG., 2. São Paulo 1978. Anais... São Paulo, ABGE/IPT. v. 1. p. 331-338.

JOHNSON, B.D. 1985. Viscous remanent magnetization model for the Broken Ridge satellite magnetic anomaly. J. Geophys. Res. 90:2640-2646.

KRUTIKHOVSKAYA, Z.A. \& PASHKEVICH, I.K. 1977. Magnetic model for the Earth's crust under the Ukranian shield. Can. J. Earth Sci. 14:2718-2728.

KRUTIKHOVSKAYA， Z.A. \& PASHKEVICH， I.K. 1979. Long-wavelength magnetic anomalies as a source of information about deep crustal structure. J. Geophys. 46:301-317.

KUYUMJIAN, R.M. \& DIAS, R.R. 1991. Anfibolitos Proterozóicos de Goiás, Brasil: Representantes de vulcanismo basal tico de arcos magmáticos ?. Geochim. Brasil. 5(1/2): 35-44.

LABRECQUE, J.L.; CANDE, S.C. \& JARRARD, R.D. 1985 Intermediate-wavelength magnetic anomaly field of the North Pacific and possible source distributions. J. Geophys. Res., 90:2549-2564.

MARANGONI, Y.R. 1994. Modelo crustal para o Norte de Goiás a partir de dados gravimétricos. 130 p. (Tese de Doutoramento, Instituto Astronômico e Geofísico da Universidade de São Paulo),

MARINI, O.J.; FUCK, R.A.; DARDENNE, M.A. \& DANNI, J.C.M. 1984 Província Tocantins, Setores Central e Sudeste. In: ALMEIDA, F.F.M. DE \& HASUI, Y. coords. O Pré-Cambriano do Brasil. São Paulo, Ed Edgard Blucher. p. 205-264.

MARSHAK, S.; ALKMIN, F.F. \& JORDT-EVANGELISTA, H. 1992. Proterozoic crustal extention and the generation of dome-and-keel structure in an Archaean granite-greenstone terrane. Nature 357:491-493.

MAYHEW, M.A.; ESTES, R.H. \& MYERS, D.M. 1985a. Magnetization models for the source of the "Kentucky anomaly" observed by Magsat. Earth Planet. Sci. Lett. 74:117-129.

MAYHEW, M.A.; JOHNSON, B.D. \& WASILEWSKI, P.J. 1985b. A review of problems and progress in studies of satellite magnetic anomalies. $J$ Geophys. Res. 90:2511-2522.

MAYHEW, M.A.; THOMAS, H.H \& WASILEWSKI, P J 1982 Satellite and surface geophysical expression of anomalous crustal structure in Kentucky and Tennessee. Earth Planet. Sci. Lett. 58:395-405.

MONTALVÃO, R.M.G. 1985a. Evolução geotectônica dos terrenos granitóide-greenstone-belt de Crixás, Guarínos e Pilar de Goiás-fiidrolina (Goiás). (Tese de Doutoramento, Instituto de Geociências da Universidade de São Paulo).

MONTALVÃO, R.M.G. 1985b. Revisão Litoestratigráfica do Supergrupo Baixo Araguaia. In: SIMP. GEOL. CENTRO-OESTE, 2. Goiânia 1985. Ata... Goiânia, SBG. p. 282-290
MOURA, C. A.V. \& GAUDETTE, H.E. 1992. Archaean zircon ages of the basement rocks of the Araguaia belt, north-central Brazil: Additional evidence of Gondwana evolution. EOS Trans. 73(14):369.

NAGATA, T. 1961. Rock Magnetism. Tokyo, Maruzen Co., Ltd. Revised Edition. 350p.

NEGI, J.G.; AGRAWAL, P.K. \& PANDEY, O.P. 1987. Large variation of Curie depth and lithospheric thickness in Indian Subcontinent and a case for magnetothermometry. Geophys. J. R. Astr. Soc. 88:763-775.

OKUBO, Y.; GRAF, R.J.; HANSEN, R.O.; OGAWA, K. \& TSU, H. 1985. Curie point depths of the island of Kyushu and surrounding areas, Japan. Geophysics, 53:481-494.

PIMENTEL, M.M. 1992. Rápido soerguimento da crosta continental no final da orogênese Brasiliana no Oeste de Goiás. In: CONGR. BRAS. GEOL., 37. São Paulo 1992. Resumos Expandidos... São Paulo, SBG. p. 312-313.

PIMENTEL, M.M. \& FUCK.R.A. 1987. Late Proterozoic granitic magmatism in southeastern Goiás, Brazil. Rev. Bras. Geoc. 17(4):414-425.

RAYMOND, C.A. \& LABRECQUE, J.L. 1987. Magnetization of oceanic crust: thermoremanent magnetization or chemical remanent magnetization ?. J. Geophys. Res. 92:8077-8088.

REGAN, R.D. \& MARSH, B.D. 1982. The Bangui magnetic anomaly: Its geological origin. J. Geophys. Res. 87:1107-1120.

RIDDIHOUGH, R.P.I972. Regional magnetic anomalies and geology in Fennoscandia: a discussion. Can. J. Earth Sci. 9:219-232.

RUDER, M.E. \& ALEXANDER, S.S. 1986. Magsat equivalent source anomalies over the southeastern United States: implications for the crustal magnetization. Earth Planet. Sci. Lett., 78:33-43.

SCHNETZLER, C.C. 1985. An estimation of continental crust magnetization and susceptibility from Magsat data for the conterminous United States. J Geophys. Res. 90:2617-2620.

SEARSON, P.H. \& HANNAFORD, W.L.W. 1957. A statistical analysis of magnetic profiles. J. Geophys. Res. 62:1-18.

SEGAWA, J. \& OSHIMA, S. 1975. Buried Mesozoic volcanic-plutonic fronts of the northwestern Pacific island arcs and their implications. Nature, 256:15-19.

SHIVE, P.N.; BLAKELY, R.J.; FROST, B.R. \& FOUNTAIN, D.M. 1992. Magnetic properties of the lower continental crust. In: FOUNTAIN, D.M.; ARCULUS, R. \& KAY, R.W. ed., Continental Lower Crust, Developments in Geotectonics 23. Amsterdam, Elsevier Sci. Publ. p. 145-177.

SHUEY, R T : SCHELLINGER, D.K · JOHNSON, EH. \& ALLEY, L.B. 1973. Aeromagnetics and the transition between the Colorado Plateau and Basin and Range provinces. Geology, 1:107-110.

SHUEY, R.T.; SCHELLINGER, O.K.; TRIPP, A.C. \& ALLEY, L.B. 1977. Curie depth determination from aeromagnetic spectra. Geophys. J. R. Astron. Soc. 50:75-101.

SPECTOR, A. \& GRANT, F.S. 1970. Statistical models for interpreting aeromagnetic data. Geophysics, 35(2):293-302.

STRIEDER, A.J. 1993. Deformação e metamorfismo na região de Santa Cruz de Goiás: correlação tectono-estratigráfica e evolução tectônica regional. 528 p. (Tese de Doutoramento, Instituto de Geociências da Universidade de Brasília).

STRIEDER, A.J. 1994. Tectônica colisional no Brasil central: evolução e implicações no padrão estrutural. In: SIMP. NAC. EST. TECTÔNICOS, 4. Belo Horizonte 1994. Anais... Belo Horizonte, SBG. p. 297-301.

STRIEDER, A.J. \& NILSON, A.A. 1992. Estudo petrológico de alguns fragmentos tectônicos da melange ofiolítica em Abadiânia (GO): I- o protolito dos corpos de serpentinito. Rev. Bras. Geoc. 22(3):338-352.

STRIEDER, A.J.; GOTTARDO, E.; CUNHA F.S.S.; BINOTTO, R.B. \& MESQUITA, M.J.M. 1994. O significado tectônico dos Lineamentos Transbrasilianos no processo colisional Neoproterozóico da Província Estrutural do Tocantins: uma hipótese de trabalho. In: CONGR. BRÁS. GEOL., 38. Balneário Camboriú 1994. Bol. Res. Exp... Balneário Camboriú, SBG. p. 267-269.

TAYLOR, P.T. 1983. Magnetic data over the Arctic from aircraft and satellites: Cold regions. Sci. Technol., 7:35-40.

TSELENTIS, G.A. 1991. An attempt to define Curie point depths in Greece from aeromagnetic and heat flow data. $P A G E O P H$. 136(1):87-101.

VACQUIER, V.\& AFFLECK, J. 1941. A computation of the average depth to the botton of the Earth's crust, based on a statistical study of local magnetic properties. Trans. Amer. Geophys. Union, p. 446-450.

XIA, H. 1986. Curie point depths of the Klamath and Cascades area in Northern California. Denver, Colorado School of Mines, Geophys. Dept., Center for Potential Field Studies. Annual Report 1985/86. p. 143-157.

MANUSCRITO A910 Recebido em 28 de fevereiro de 1997 Revisão dos autores em 24 de abril de 1997 Revisão aceita em 27 de abril de 1997 